\title{
ОСНОВНЫЕ ПРИНЦИПЫ, ОКАЗЫВАЮЩИЕ ВЛИЯНИЕ НА СТОИМОСТЬ СИНЕРГЕТИЧЕСКОГО ЭФФЕКТА
}

\author{
(c) 2019 Зимин Владислав Владимирович \\ аспирант \\ Финансовый университет при Правительстве Российской Федерации, Россия, Москва \\ E-mail: vladislav14@rambler.ru
}

Сделка по слиянию или поглощению должна опираться на взаимовыгодные условия для обеих сторон: как компании-цели, так и компании-покупателя. Определение стоимостной оценки синергетического эффекта на практике достаточно затруднительно из-за множества факторов. Именно поэтому необходимо выделить ряд принципов, оказывающих влияние на процедуру количественного определения стоимости синергетического эффекта.

Ключевые слова. Синергетический эффект, сделки по слиянию и поглощению, принципы оценки, стоимостная оценка, определение стоимости.

Одним из основных принципов эффективного развития компании является рациональное использование её ресурсов (капитала, труда, земли и предпринимательских способностей). При осуществлении сделки слияния и поглощения ресурсы компаний объединяются, что приводит к формированию синергетического эффекта. Синергетический эффект - это эффект, возникающий вследствие совместного взаимодействия элементов в системе, который приводит к увеличению эффективности от различных видов деятельности объединяющихся компаний [14].

Расчет числового результата синергии от сделки слияния и поглощения в теории не имеет математической формулы, с помощью которой можно было бы определять его значение. На практике, к сожалению, для вычисления стоимостной оценки синергетического эффекта учет всех факторов невозможен ввиду неполноты или асимметрии информации как на начальных, так и на завершающих этапах сделки. В данной статье целью автора является выявление принципов, влияющих на оценку эффективности интеграции компаний, а именно на числовой показатель синергетического эффекта от сделок слияния или поглощения.

Для того чтобы узнать выгодна сделка или нет, необходимо брать в расчет все факторы и критерии, которые оказывают воздействие на процесс интеграции компаний. Процедура определения синергетического эффекта представляет собой некий механизм, строящийся на основе принципов, которые непосредственно влияют на этот эффект [17]. Условно ученые-экономисты их делят на:

- принципы, вытекающие из составляющих синергизма;

- принципы интеграции компаний;

- принципы оценки стоимости предприятия.

Кроме того, в ходе написания статьи были выделены принципы достижения синергетического эффекта за счет изменения микро- и макросреды, предельной производительности, стоимости, неполноты информации и прогрессии.

Стоит выделить три компоненты синергизма: прибыль, расходы и инвестиции компании, на которых строится ряд принципов. На основе прибыли формируется принцип накопления капитала, который представляет собой увеличение имеющихся средств компании для производства за счет доходности. Следующим принципом выступает материальная мотивация сотрудников компаний, выраженная в их денежном поощрении за перевыполнения плана. К прибыли, полученной компаний, относят принцип сокращения доходов и принцип уплаты налогов.

Следующий элемент синергии - расходы компании, определяющие принцип механизации управления издержками [7]. Сущность его заключается в эффективном управлении издержками обращения, которое способствует снижению расходов фирмы.

Третьим компонентом синергизма являются инвестиции, которые неразрывно связаны с созданием именно ликвидного, высокодоходного и 
с соответствующим уровнем безопасности инвестиционного портфеля.

В процессе сделок слияния и поглощения проявляется синергетический эффект, который и обуславливает принципы интеграции компаний. Так, например, принцип объединения характеризуется отношением компаний-оппонентов друг к другу.

Принцип эффективного распределения внутренней структуры компании предполагает сокращение кадров, которые дублируют свой функционал в результате интеграции компаний. Важно учитывать, что текучесть кадров может отрицательно сказаться на стоимостной оценке синергетического эффекта. Для того, чтобы это предотвратить компании необходимо разработать мотивационную систему поощрения персонала, проводить мероприятия, поддерживающие сплоченность трудового коллектива. Лицо компании - это её сотрудники, от которых зависит успех предприятия. Компании для получения положительного синергетического эффекта необходимо организовать коммуникацию между сотрудниками, которая будет способствовать повышению работоспособности сотрудников компании и, соответственно, росту самой компании. Кроме того, сотрудники должны осознавать свои обязательства и понимать, на что направлена их трудовая деятельность, для этого компания должна четко ставить и распределять цели между ними, а также ввести систему премий за перевыполнение плана[10].

Стоит отметить, что при слиянии и поглощении компании происходит смешение корпоративной культуры, где срабатывает принцип возраста компании (времени нахождения на рынке) [3]. В связи с этим автором была выявлена зависимость между возрастом компании и эффективностью ее интеграции. Например, если компания-цель старше и с более устоявшейся на протяжении нескольких лет корпоративной культурой, чем компания-покупатель, то процесс интеграции может не произойти из-за того, что сотрудники могут не принять новую молодую корпоративную культуру, что станет препятствием к созданию единой организационной культуры. На основе этого был выделен принцип гармонизации корпоративной культуры, который важен при получении результата синергетического эффекта [8].

Принцип управления рисками предприятия присутствует на протяжении всех этапов сделки слияния и поглощения, начиная от выбора стратегии и заканчивая неправильной оценкой стоимости компании. На рынке присутствует риск неверного выбора объекта покупки из-за неполноты информации: увеличение расходов на сделку, ошибочная оценка компании-цели, что может спровоцировать отрицательный синергетический эффект, то есть сделка будет невыгодна обеим сторонам [13]. Следующим принципом является принцип коррекции, помогающий избежать неблагоприятного результата сделки. Топ-менеджеры при разработке стратегии могут не учесть некоторые аспекты, которые были допущены из-за неполноты или асимметрии информации на начальных этапах. Но их главная задача состоит в том, чтобы своевременно добавлять новые факторы, оказывающие влияние на количественную и качественную оценку показателя синергетического эффекта.

После завершения сделки слияния и поглощения компании необходимо решить вопрос с избытком менеджеров с помощью принципа результативного управления, оставляющий решение за фирмой, которая вправе как сократить сотрудников, так и предложить им другие должности.

Ещё одним принципом, оказывающим влияние на синергетический эффект, является принцип инвестирования, включающий в себя инвестиционную деятельность, которая представляется в виде сложной структуры взаимосвязанных элементов, для эффективной работы которых необходима их систематизация. Например, систематизирование поступлений доходов и расходов облегчает компании процесс принятия решений.

Следует учитывать риск конкуренции на рынке, существующей в любом виде деятельности. Если рынок не монополизирован, и на нем представлены две одинаковые компании-цели, но стоимость одной из них завышена, то компания-покупатель будет делать выбор в пользу более выгодной сделки. Соответственно, у компании-цели с более высокой стоимостью появляется мотивация к её снижению. Из вышесказанного можно сделать вывод, что на синергетический эффект оказывает влияние не только внутренние, но и внешние факторы. Отсюда, выделен принцип изменения внешней среды, который заключается в том, что такие факторы, как: размер и диверсификация рынка, политическая стабильность, качество жизни населения 
также воздействуют на стоимость компании и, соответственно, на стоимостную оценку синергетического эффекта.

Принципы оценки стоимости бизнеса немаловажны при получения стоимостного показателя синергетического эффекта. Именно от стоимости компании-цели зависит и результат сделки. Стоимость бизнеса зависит от полезности, доходности предприятия, а также, как мы уже выяснили, от рыночной среды. Кроме того, при стоимостной оценке фирмы стоит учитывать активы и обязательства предприятия.

Определяя стоимость бизнеса, следует учитывать принцип полезности, который объясняется тем, что компания должна быть полезна для общества, должна удовлетворять его потребности. В противном случае, такая компания не имеет смысла существования, так как рынок формируют не только продавцы, но и покупатели, которые задают спрос на продукцию. Отсюда можно сделать вывод, что чем полезнее бизнес, тем более он востребован, а значит, и стоимость его активов значительно выше.

Далее возникает принцип замещения, который, основываясь на полезности фирмы, показывает нам, что если на рынке присутствуют другие компании с аналогичной полезностью, то максимальная стоимость бизнеса не сможет превышать установившегося уровня цен. При сделке слияния и поглощения проходит определённое время с момента подписания соглашения и до успешного функционирования компании, в связи с этим необходимо принимать во внимание принцип ожидания, учитывающий фактор времени и основывающийся на методе дисконтирования денежных потоков, который показывает стоимость будущих доходов к текущей стоимости.

Следующим принципом, определяющим стоимость компании, является принцип доходности, ведь, доходность зависит от эффективного использования всех факторов производства. Чтобы управлять ресурсами с большей отдачей автором был выделен принцип вклада, который контролирует каждый фактор производства по отдельности, так, чтобы расходы на его приобретение не превышали сумму его доходности и, соответственно, увеличивали стоимость самой компании.

Выделяя принцип вклада, стоит учитывать принцип предельной производительности и сбалансированности. Приобретение определён- ного фактора производства в избытке может привести к снижению его производительности, что приведет к тому, что доход от такого фактора станет убыточным. Важной особенностью является сбалансированность факторов производства, то есть все ресурсы производства должны быть в равном соотношении, которое будет приносить наибольший доход компании. Здесь стоит учитывать и размер компании, и диверсификацию рынка. Все это должна содержать в себе стратегия развития компании, для того чтобы после завершения сделки слияния и поглощения компания могла быстро и без потерь оптимизировать в работе все факторы производства.

На стоимость бизнеса также влияет рынок и механизмы спроса и предложения. В теории равновесная цена устанавливается в точке пересечения кривой спроса и предложения, где продавцы готовы продавать, а потребители покупать товар по данной стоимости. Но на практике все гораздо сложнее, существует огромное количество факторов, которые влияют на установление цены. Принцип соответствия строится на том, что зачастую рынок сам устанавливает среднюю стоимость бизнеса, которая устраивает львиную долю рынка и соответствует их ожиданиям. В противном случае, компании бы несли убытки и уходили с рынка.

Принципы прогрессии и регрессии находят свое начало в принципе соответствия. Принцип прогрессии наблюдается, когда в результате совместного функционирования смежных компаний рыночная стоимость предприятия будет выше. Если предприятие вводит излишние улучшения в рыночной среде, то начинает действовать принцип регрессии, и стоимость данной компании может быть завышена, что приведет к несоответствию ожидаемого и конечного результата синергетического эффекта [16].

В процессе написания статьи были выделены ряд принципов, оказывающих влияние на стоимость синергетического эффекта такие, как:

- Принцип вклада помогает определить: насколько эффективно используется один компонент сделки слияния или поглощения, который оказывает влияние на общую величину синергетического эффекта. Например, если при подборе персонала администрация будет оценивать только профессиональные качества сотрудников, тогда есть вероятность того, что из-за своих знаний работник может быть не принят в коллектив и, соответственно, не сможет до конца проявить 
себя и свои способности, что приведет к низкой работоспособности. Но, если же администрация будет смотреть не только на профессиональные навыки, но и на те качества, которые позволят ему быстрее влиться в коллектив, тогда работник может с помощью коллег показать результат выше ожиданий.

- Принцип предельной производительности основан на теории предельной полезности, что позволяет рассматривать его совместно с синергетическим эффектом. После завершения сделки слияния или поглощения компаний возникает синергия, выражающаяся в экономии средств за счет друг друга, но постепенно этот эффект идет на убывание. Для расчета числового результата синергетического эффекта необходимо состояние до и после объединения компаний. Но на практике это практически невозможно осуществить, так как в период до - это две отдельные компании, после же сделки - это уже одна органическая компания, которая с течением времени меняется и поддается влиянию жизненных циклов, поэтому возникает проблема в неосуществимости сравнения этих компаний до и после сделки слияния или поглощения.

- Принцип прогрессии выражен в синергии как более высокой оценки данной компании, чем её рыночная стоимость, за счет эксплуатирования или использования объектов улучшенной инфраструктуры соседних предприятий.

- Принцип изменения внешней среды характеризуется тем, что экономические, политические, социальные и культурные явления влияют и на компанию и на стоимостную оценку ее синергетического эффекта. Для того, чтобы предприятие на рынке было более устойчиво, необходимо развивать гибкую систему управления, которая будет способна принимать правильные решения в любых условиях (последствия кризисов, введение международных санкций, нестабильность национальной валюты и пр.).
- Принцип изменения стоимости заключается в развитии событий с течением времени с момента заключения сделки слияния или поглощения. Количественную оценку синергетического эффекта можно получить с помощью метода дисконтирования денежных потоков, приведя будущие доходы к текущей стоимости.

Все вышеприведенные принципы тесно связаны между собой и непосредственно влияют на стоимостную оценку синергетического эффекта. Они показывают основные закономерности формирования механизма построения оценки синергии. Но при осуществлении реальных сделок слияния или поглощения существуют множество других факторов, которые могут ошибочно определить стоимость синергии.

Таким образом, проанализировав понятие, методы и механизм оценки синергетического эффекта, были выделены не только принципы, вытекающие из составляющих синергизма, принципы интеграции компаний, принципы оценки стоимости предприятия, но и дополнительные принципы, которые помогают в формировании стоимостной оценки синергетического эффекта. Были выявлены следующие принципы: принцип вклада, принцип изменения внешней среды, принцип предельной полезности, принцип прогрессии, принцип изменения стоимости.

Стоит отметить, что компании должны учитывать принцип сбалансированности и мгновенной корректировки при сделке слияния и поглощения, которые позволяют более эффективно и быстро осуществлять процесс интеграции компаний.

Другим важным составляющим механизма оценки сделки слияния и поглощения являются сотрудники фирмы, которые способствуют достижению целей компании. Для этого ей необходимо позаботиться об атмосфере в коллективе и сделать так, чтобы каждый работник компании чувствовал себя частью целого.

\section{Библиографический список}

1. Боди 3., Кейна А., А. Дж. Маркус. Принципы инвестиций, изд: Вильямс, 2018, с. 984

2. Генске М.А. Оценка эффективности и не эффективности слияний и поглощений // Менеджмент в России и за рубежом. 2004. № 6. С. 73-79.

3. Гохан П. Слияния, поглощения и реструктуризация компаний. Изд. Альпина Паблишер, 2015, с. 744

4. Иванов А.Е. Априорная оценка синергетического эффекта интеграции на основе нечетко-множественной модели определения коэффициента синергетического роста // Экономический анализ: теория и практика. 2012. № 42(297). C. 33-42 
5. Козенкова Т.А. Методические подходы к оценке синергетического эффекта финансово-экономической интеграции // Стратегии бизнеса. 2014. № 1(3). С. 51-62

6. Козенкова Т.А., Адамов Н.А. Факторы и показатели синергетического эффекта интеграции // ГОУвПО «Государственный университет управления». Вестник университета, 2007.-№ 10.

7. Коржов А.О. Структура затрат на производство и реализацию продукции на предприятии: проблемы и пути совершенствования: маг. дисс. Уральский фед. университет, Екатеринбург, 2017

8. эй А., Шелтон М. Человеческий фактор в слияниях // Вестник McKinsey. 2003. № 2. С. 54-62.

9. Левин А. А. Мотивы слияний и поглощений в корпоративном секторе экономики // Финансы и кредит. 2007. № 21. C. 33-37

10. Матюшок А.В. Основные принципы слияний и поглощений международных компаний. Вестник РУДН, сер. Экономика, 2007, № 3-4. С. 36-С.44

11. Савчук С.В. Анализ основных мотивов слияний и поглощений // Менеджмент в России и за рубежом. 2002. № 5. С. 45-67.

12. Сергеев И.Б., Пономоренко Т.В. Формирование и оценка синергетических эффектов при интеграции горных компаний //Отдельные статьи Горный информационно-аналитический бюллетень (препринт) с.316-323. 2013

13. Фадейкина Н.В., Максимова В.Л. Сделки слияния и поглощения: понятие и виды, этапы эволюции и основные принципы осуществления. Финансы и кредит № 4, 2011С.67-75

14. Финогенова Е.А. Синергетический эффект: подходы к определению и классификация. Вестник науки и образования № 5 (29), 2017 с. 69-72

15. Халикова Д.О. Основные виды синергетических эффектов при слияниях и поглощениях нефтегазовых компаний. Нефтегазовое дело, № 3 (11), с. 165-169, 2013

16. Экономика недвижимости: Учебное пособие / Сост.: Я.В. Паттури; НовГУ им. Ярослава Мудрого.-Великий Новгород, 2002.- с. 31

17. Эскиндаров М.А. Оценка стоимости бизнеса: учебник под ред., М.А. Федотова под ред.- Москва: КноРус, 2018. - 320 с. - Для бакалавров 